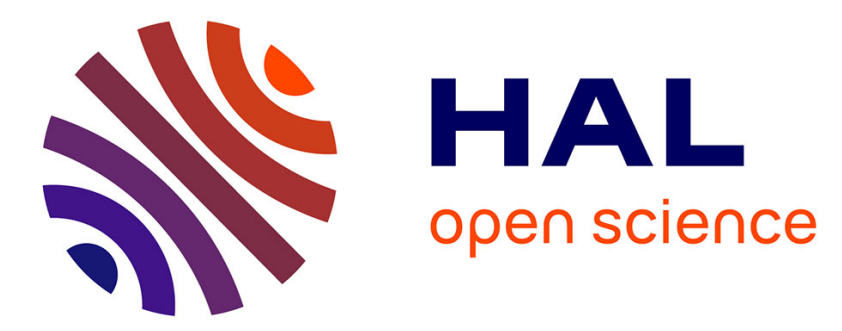

\title{
Prevalence and nature of statin drug-drug interactions in a university hospital by electronic health record mining
}

Camille Morival, Richard Westerlynck, Guillaume Bouzillé, Marc Cuggia, Pascal Le Corre

\section{- To cite this version:}

Camille Morival, Richard Westerlynck, Guillaume Bouzillé, Marc Cuggia, Pascal Le Corre. Prevalence and nature of statin drug-drug interactions in a university hospital by electronic health record mining. European Journal of Clinical Pharmacology, 2018, 74 (4), pp.525-534. 10.1007/s00228-017-2400-6 . hal-01743767

HAL Id: hal-01743767

https://hal-univ-rennes1.archives-ouvertes.fr/hal-01743767

Submitted on 12 Apr 2018

HAL is a multi-disciplinary open access archive for the deposit and dissemination of scientific research documents, whether they are published or not. The documents may come from teaching and research institutions in France or abroad, or from public or private research centers.
L'archive ouverte pluridisciplinaire HAL, est destinée au dépôt et à la diffusion de documents scientifiques de niveau recherche, publiés ou non, émanant des établissements d'enseignement et de recherche français ou étrangers, des laboratoires publics ou privés. 


\section{$\underline{\text { Title Page }}$}

Title : Prevalence and nature of statins drug-drug interactions in a university hospital by electronic health records mining using five drug databases

Short title: Prevalence of drug-drug interactions of statins

First author's surname : Morival

\section{Authors' names, academic degree, and affiliations:}

Camille Morival ${ }^{\mathrm{a}-\mathrm{b}-\mathrm{d}-\mathrm{f}}$ PharmD, Richard Westerlynck ${ }^{\mathrm{b}-\mathrm{c}-\mathrm{d}-\mathrm{e}}$ MSc, Guillaume Bouzillé ${ }^{\mathrm{b}-\mathrm{c}-\mathrm{d}}$ MD, Marc Cuggia ${ }^{\mathrm{b}-\mathrm{c}-\mathrm{d}} \mathrm{MD}, \mathrm{PhD}$ and Pascal Le Corre ${ }^{\mathrm{a}-\mathrm{f}} \mathrm{PharmD}, \mathrm{PhD}$

a) CHU Rennes, Pôle Pharmacie, Service Hospitalo-Universitaire de Pharmacie, F-35033 Rennes Cedex, France.

b) CHU Rennes, CIC Inserm 1414, Rennes, F-35000, France

c) CHU Rennes, Centre de Données Cliniques, Rennes, F-35000, France

d) Université de Rennes 1, LTSI, Inserm U1099 Rennes, F-35000, France

e) Ecole nationale de la statistique et de l'analyse de l'information, F-35000, Rennes

f) Laboratoire de Pharmacie Galénique, Biopharmacie et Pharmacie Clinique, IRSET U1085, Faculté de Pharmacie, Université de Rennes 1, F-35043, Rennes Cedex, France.

\section{Corresponding author :}

Pr. Pascal Le Corre,

Laboratoire de Pharmacie Galénique, Biopharmacie et Pharmacie Clinique,

Faculté de Pharmacie

Université de Rennes 1, 35043 Rennes Cedex, France. 


\title{
Corresponding author :
}

Phone +33223234872

Fax +33223234846

Email: pascal.le-corre@univ-rennes1.fr

Word count: 4389

Key words: statins, pharmacokinetics, drug-drug interactions, metabolic enzymes, drug transporters, drug databases, data mining, clinical data warehouse

\begin{abstract}
$\underline{\text { Abstract }}$
Aim :

Our aim was to describe prevalence, nature and level of severity of potential statins drug-drug interactions in a university hospital, and the agreement between five drug databases.
\end{abstract}

\section{Methods :}

In a cross sectional study, statins drug-drug interactions were screened from medical record of 10,506 inpatients treated stored in the clinical data warehouse "eHOP". We screened the drug-drug interactions using Micromedex, Drugs.com, Vidal, Theriaque and Thesaurus. Prevalence of drug-drug interactions was analyzed for each statins and by level of severity.

\section{Results :}

Between $22.5 \%$ and $52.2 \%$ of patients were exposed to at least one statin drug-drug interaction depending on the drug database. Given their lipophilicity and CYP3A4 metabolic pathway, atorvastatin and simvastatin presented a higher prevalence of drug-drug interactions while fluvastatin presented the lowest prevalence. Up to $1 \%$ of the patients was exposed to a 
contraindicated drug-drug interaction, the most frequent drug-drug interaction involving influx-transporter interactions between simvastatin or rosuvastatin with ciclosporine. The second most frequent contraindicated drug-drug interaction involved CYP3A4 interaction between atorvastatin or simvastatin with either posaconazole or erythromycin. Furthermore, our analysis showed some discrepancies among drug databases in the prevalence, and in the nature of drug-drug interactions.

\section{Conclusions:}

Different drug-drug interaction profiles were observed between statins with a higher prevalence of CYP3A4-based interactions for lipophilic statins. Contraindicated drug-drug interactions were mainly reported for transporters-based interactions involving OATP1 influx transporters. These points are of concern to obtain safer statins prescriptions. Discrepancies observed among drug databases challenge the management of statins drug-drug interactions by health professionals. 


\section{1 - Introduction}

Statins are widely prescribed across the world and have proven benefits in reducing the rate cardiovascular disease. During 2011-2012, the National Health and Nutrition Examination Survey (USA), informed that more than one-quarter (27.9\%) of adults aged 40 and over, reported using a prescription cholesterol-lowering medication in the past 30 days. Among US adults treated by cholesterol-lowering medication, 93\% used statins with simvastatin as the most prescribed statins [1]. In France, atorvastatin was the most prescribed statin at the same period [2]. Statins have an acceptable side-effect profile with mild musculoskeletal problems, such as myalgia associated with muscle problems in approximately $10 \%$ to $25 \%$ of patients treated in clinical practice [3]. The incidence of rhabdomyolysis, life-threatening adverse drug reaction, was estimated to 3.4 per 100,000 patients per year in cohort studies. It has been reported that this incidence was different amongst the statin used. The frequency of rhabdomyolysis was higher (4.2 per 100,000 patients per year) with lovastatin, simvastatin, or atorvastatin which are metabolized by CYP3A4, than with pravastatin or fluvastatin which are not substrate of CYP3A4. Sixty percent of the cases of rhabdomyolysis reported in patients taking statins which are substrate of CYP3A4 [4]. This suggests that avoiding drug-drug interactions which affect some statins such as atorvastatin and simvastatin is of clinical interest to reduce potential drug-drug interactions (DDI)-related adverse drug reactions.

Statins have rather similar pharmacodynamics and toxicologic properties, while they differ on their pharmacokinetic properties as a result of differences in physico-chemical properties, and hence in their interactions with biological environment. These differences should be carefully considered to understand the different nature of drug interactions within statins occurring at the level of drug metabolism and/or at the level of membrane transporters (influx and efflux). Given that patients taking statins are polymedicamented [5], avoiding drug-drug interactions 
(DDI) and subsequent potential adverse drug reactions is of concern to optimize patient management. In a recent systematic review, the prevalence of DDI's with statins has been variable ranging from $0.2 \%$ to $33 \%$ depending on the interacting combinations studied, on the source (out- or in-patient records or primary care-databases) and on the drug interaction database used [6]. The prevalence of clinically-relevant DDIs ranged from 1.5 to $4 \%$. However, this difference in prevalence was not unlikely given that most of the studies either searched DDI's with pre-defined interaction pairs or focused only on CYP3A4 inhibitors, or have used different DDI screening program. The only study analyzing all potential DDI's of statins found a prevalence of $8.6 \%$ in ambulatory setting using Micromedex with a higher frequency for atorvastatin and simvastatin compared to fluvastatin and pravastatin (DrugReax DDI screening program) [7].

To better understand the origin (CYP450- or transporter-based DDI) and the DDI pattern of statins, we determined the prevalence, nature and level of severity of all potential drug-drug interactions of statins from electronic health records stored in our clinical data warehouse. Given the clinical significance of some DDIs with statins, and to the fact that clinicians have access to different DDI screening program according to their computerized physician orderentry system, we carried out this work with a comparison of five drug databases (DDBs).

\section{2 - Materials and Methods}

2.1- Research strategy on statin pharmacokinetics 
We searched information on physico-chemical and pharmacokinetic properties of statins in the scientific literature through PubMed with the following Mesh (Medical Subject Heading) terms : statins, pharmacokinetics, drug-drug interactions, CYP450, transporters, and through PharmGKB, UCSF-FDA transportal and Drugbank databases.

2.2 - Detection of statin's DDI in our clinical data warehouse "eHOP"

\subsubsection{Selection of drug databases (DDBs)}

To obtain DDI information, we selected DDBs which are commonly used by health professionals in France (i.e., Thesaurus, Vidal and Theriaque) and in the United States (i.e., Micromedex and Drugs.com).

Thesaurus (version: 2016-08-12) [8], is a list of clinically relevant DDIs made as a tool to support decision making. This document is published by the Drug interaction working group of the French National Agency of Medicine and Health Products safety. This working group represented by an experts panel use specific criteria for inclusion and severity assessment of DDI based on DDI evidence sources. DDI screening program from Vidal, a private-funded subscription DDB, (version: 2016-08-17) [9] and Theriaque, an open-access public-funded DDB (version: 2016-08-24) [10], are mainly based on Thesaurus DDB but some DDI can be added based on their internal literature review process.

Then, according to a recent systematic review [11], we selected two most commonly referenced US DDBs : Drugs.com as open access private-funded DDB (version: 2016-08-10) [12] and Micromedex as a private-funded subscription DDB (version: 2016-08-10) [13]. DDI information was manually extracted from each DDBs. For Micromedex DDB, information 
related to clinical management of DDIs were extracted from DRUG-REAX® System in the section clinical management, available in the interaction detail of DDIs [13].

For each selected DDB, a list of DDIs for each statin has been generated and classified according to different level of severity. Statin DDIs for each DDB have been organized in datasets using OrientDB database management system. This software and data queries enabled us to request information in our clinical data warehouse.

\subsubsection{Clinical Data Warehouse}

Drug administrations were collected using the clinical data warehouse (CDW, formerly called eHOP [14]) of the university hospital of Rennes. Patient consent was waived since the design of the retrospective cross-sectionnal study was non-interventional.

In order provide an accurate detection of DDI, we also documented the half-life of each statin (Table 1). We included every patient which was treated with statins. The screening of potential interactions was performed during each patient hospital stay.

The study was performed on a 18-month period (January 2015 to June 2016). The prevalence (\%) of DDI was defined by the ratio of patients exposed to at least one DDI to the total number of patients.

Each DDI was counted only once per patient per level of severity even though the patient was re-hospitalized, and whatever the duration of the hospital stay (i.e., number of administration). However, the patient was counted twice if one DDI of severity 1 and a DDI of severity 2 were revealed in the identification (See section 2.2.3). Prevalence of DDI according to databases 
were compared and expressed in percentage point differences. The authors take responsibility for the data analysis integrity.

2.2.3 Mapping of DDBs’ grading systems

Differences in terminologies and in the grading systems used to classify DDIs have been observed between DDBs. However, the common point of our selected DDBs is the information dealing with the clinical management. Hence, in order to compare the different DDBs, we define a mapping of DDB's grading systems. We selected the first three levels of the french grading system as reference to align information from US DDBs. Indeed, level « to take into account » (i.e., level 4) characterizes a DDI of minor clinical significance and was not identified in our analysis

To identify DDIs, French DDBs use a grading system based on the clinical management which comprises 4 levels of severity :

- Contraindication (i.e., Contre-indication): Combination with serious or unpredictable risk, existence of possible alternatives.

- Should be avoided (i.e., Association déconseillée): Relative contraindication, combination with severe potential risk possible if justified. Monitoring required.

-Precaution for use (i.e., Précaution d'emploi): Combination is possible if recommendations are followed: clinical and biological monitoring or therapeutic drug monitoring or adjusting doses. 
-To take into account (i.e., A prendre en compte): no specific recommendation, no specific clinical management.

Drug.com and Micromedex use a grading system based on a level of risk whose different levels of severity are: contraindicated, major, moderate, minor and unknown. These DDBs add to their description of DDIs, clinical management information in an unstructured format (ie-full-text). Consequently, we extracted information related to DDIs clinical management documented in Drugs.com and Micromedex and performed a mapping on the French grading system.

The mapping between the US and French DDBs' grading system is described in Figure 1.

Micromedex Drug-Reax ${ }^{\circledR}$ system mentions the clinical management of each DDI in a specific paragraph. The clinical management recommendations were analyzed by a pharmacist who assigned a grade for every statin DDI. The mapping was performed using the keywords listed in Figure 1.

Drugs.com had for each DDI, one expression which characterized clinical management. Those expressions are listed in Figure 1. The mapping between Drug.com and French DDBs are also described in Figure 1.

We decided to consider DDIs of levels of severity 1, 2 and 3 (Figure 1). DDI assigned with these levels of severity imply a clinical decision and consequently a warning to physicians. 


\section{3 - Results}

\section{1 - Pharmacokinetic differences between statins (Table 1, Figure 2)}

Data in the literature [15-20], clearly showed difference in physico-chemical properties between statins, especially in lipophilicity (predicted $\log \mathrm{P}$ ) and in pharmacokinetic properties. Indeed, there is a decrease in lipophilicity in the following rank-order : Simvastatin > Atorvastatin $>$ Lovastatin $>$ Fluvastatin $>$ Pravastatin $>$ Rosuvastatin (Table 1).

As shown in Table 1, lipophilicity is a factor governing the intensity and mechanism of passage through cell membranes as well as the interaction with biological systems (plasma proteins, drug-metabolizing enzymes and drug transporters).

The hepatic metabolism of lipophilic statins is mediated primarily by CYP3A4, and secondarily by CYP2C8. The two most hydrophilic statins (i.e., rosuvastatin and pravastatin) are not extensively metabolized; and the CYP pathway is of minor significance.

Lipophilic statins preferentially diffuse through membranes of enterocytes and hepatocytes by passive diffusion while diffusion of hydrophilic statins involves influx transporters (from OATP family) within these cell membranes (Figure 2). Moreover, efflux transporters from the $\mathrm{ABC}$ family localized at the apical site of the enterocytes and at the hepatocyte-biliary interface can also be involved in the passage through membranes decreasing the absorption at the intestinal level and increasing the elimination in the bile at the hepatocyte level. Hence, the handling by influx and efflux transporters which is also influenced by the lipophilicity has to be considered as a variation factor in statin pharmacokinetics, and as a potential source of drug-drug interactions. 


\section{2 - Detection of statin DDI in our warehouse "eHOP"}

The study population included 10,506 hospitalized patients whose median length stay was about 7 days. The median age of included patients was 72 years ranging from 19 to 98 years. In this population, $69.1 \%$ of patients were treated by Atorvastatin, $24.1 \%$ by Pravastatin, $13.1 \%$ by Fluvastatin, $11.3 \%$ by Rosuvastatin and $11.0 \%$ by Simvastatin.

The prevalence of statins DDIs (all levels considered) was equal for the French DDBs (Vidal and Theriaque) whose information relies mainly on Thesaurus DDB. Micromedex had a slightly higher prevalence of total interactions (around $+7 \%$ ) while Drugs.com prevalence was almost twice-higher (52.2\%). (Table 2)

A more detailed analysis of DDI's prevalence indicated where the difference comes from (Table 3). The difference in level of severity 1 DDI (i.e., contraindication) is rather small, showing a slight variation between Micromedex (17) and Thesaurus (22). The main difference appears in level 2 severity (i.e., should be avoided) with a 5-fold variation in prevalence. Both US DDBs displayed a higher prevalence in level 2 severity DDI's. With regard to level 3 severity DDI's, Micromedex and the French DDBs performed quite similarly while DDI prevalence from Drugs.com was twice higher (around $50 \%$ ).

In the Figure 4, we present the prevalence of DDI classified for each statin by level of severity and by DDB. 


\subsubsection{Dissimilarities between DDBs for each level of severity}

\section{Level 1}

If we focus on French DDBs (Thesaurus, Vidal and Theriaque), we observe similar prevalence of DDIs on simvastatin, pravastatin, atorvastatin and fluvastatin at the level of severity 1 (Figure 4). Conversely, we observed different prevalences for rosuvastatin depending on the DDB selected (e.g difference of $0.2 \%$ ).

Level 1 DDI's in Micromedex and Drugs.com presented equal prevalence for every statins.

Then, comparison of DDI's prevalence between French and US DDBs showed a higher prevalence in French DDBs for atorvastatin and especially for rosuvastatin. Conversely, for Micromedex and Drugs.com the prevalence was higher for simvastatin (1.2\% vs $0.3 \%)$.

Identification of the specific DDI's at level of severity 1 are illustrated in Figure $3 a$ (3 most frequent DDIs assessed with level of severity 1). For fluvastatin and pravastatin, no interactions were identified whatever the DDBs.

\section{Level 2}

French DDBs present very similar prevalence of statin DDIs. Indeed, Thesaurus and Vidal led to the same prevalence for each statin. However, Theriaque showed some slight differences on DDI's prevalence with a higher prevalence for simvastatin and pravastatin $(+0.4 \%$ and + 
$0.2 \%$ respectively); a lower prevalence for rosuvastatin $(-0.2 \%)$ and a similarity for atorvastatin and fluvastatin.

Compared to Micromedex, Drugs.com displayed a higher prevalence of DDI's, excepted for fluvastatin. The difference was significant for simvastatin (26\% vs $4.6 \%)$ and smaller for Rosuvastatin (2.9\% vs $0.3 \%)$.

At level 2 of severity, differences observed between French and US DDBs were higher than between DDBs of the same country for atorvastatin, fluvastatin and pravastatin. It should be noticed that Drugs.com identified a higher prevalence than all other DDBs: $+25 \%$ for simvastatin compared to French DDBs; and $+22 \%$ compared to Micromedex.

Compared to French DDBs, Micromedex showed a higher prevalence for all statins excepted for rosuvastatin. The difference in prevalence was in the following order : atorvastatin (+ $5.5 \%)$, simvastatin and pravastatin (around $+3.0 \%)$, and fluvastatin $(+0.2 \%)$.

Identification of the specific DDI's at level of severity 2 are illustrated in Figure $3 b$ (3 most frequent DDIs assessed with level of severity 2)

\section{Level 3}

French DDBs present similarity in DDIs' prevalence for each statin. However, US DDBs present dissimilarities in DDI's prevalence for atorvastatin and pravastatin $(+29 \%$ and $+13 \%$ for Drugs.com compared to Micromedex, respectively). 
It should be noticed that US DDBs detected more DDIs than French DDBs for all statins excepted for Pravastatin. Identification of the specific DDIs are illustrated in Figure 3c (3 most frequent DDIs assessed with level of severity 3).

\title{
3.2.2 Differences between statins
}

\begin{abstract}
All DDBs and levels of severity considered, we observed more DDIs for atorvastatin and simvastatin while fluvastatin was the statin whose DDI's prevalence was the lowest. Considering level of severity 1 , the statin presented the highest prevalence of DDIs was rosuvastatin according to French DDBs, and simvastatin according to US DDBs.
\end{abstract}

\section{4 - Discussion}

\subsection{Statins pharmacokinetics}

Lipophilicity is known to impact the pharmacokinetic pathway of statins either through differences in metabolism and/or handling by membrane transporters. Hence, the nature and frequency of DDI's may potentially differ between statins.

Interactions with the most lipophilic statins (simvastatin, atorvastatin and lovastatin) which are CYP3A4 substrates are to be considered as a result of their frequency since there are a significant number of CYP3A4 inhibitors used clinically [17]. This is clearly shown in our study where atorvastatin and simvastatin clearly displayed the higher frequency of DDI's reaching around $35 \%$ to $45 \%$ respectively according to Micromedex DDB (Figure 4). It could be anticipated that lovastatin (not studied in our study because not available in France) 
which is a highly lipophilic statin mainly metabolized by CYP3A4 could have the same DDI profile given [16].

The CYP2C9 substrate statin (fluvastatin) and the hydrophilic statins, especially pravastatin and to a lesser extent and rosuvastatin, had much lower frequencies of DDI's (Figure 4). Pitavastatin (not studied in in our study because not yet available in France) which has a physico-chemical and metabolic profile close to that of fluvastatin might have a low DDI profile.

It is noteworthy that level-1 severity interactions involved mainly influx-transporter interactions and not CYP3A4 interactions. Even though our study showed that OATP-based drug interactions were not so frequent, reaching around $1 \%$, with cyclosporine as precipitant drug, it should be noticed that these DDI's were ranked as level-1 severity (i.e., contraindication). It should also be noticed that Micromedex and Theriaque showed a dissimilarity for DDI with cyclosporine. Indeed, simvastatin-cyclosporine and rosuvastatincycloporine were considered as level-1 severity in Micromedex and Theriaque, respectively.

If CYP3A4-based DDI are quite well known, as well as the main drug precipitant, transporter-based interactions deserve to be more considered by health professionals; especially DDI involving influx transporters at the hepatocyte level.

Since OATP-mediated hepatic uptake can be a rate-limiting step in hepatic clearance of statins, significant DDI can occur because extensive inhibition of these transporters can be achieved in clinical setting; especially via inhibition of OATP 1B1, and to a lesser extent of via inhibition of OATP1B3 [21]. Indeed, above 5-fold increase in AUC (FDA threshold to be considered as clinically significant DDI) have been observed when cyclosporine or rifampin have been co-administered with some statins whatever their lipophilicity [22]. These interactions involving membrane transporters are of the order of magnitude of those observed 
with inhibition of the CYP3A4 enzyme. Based on these observations, the co-prescription of OATP 1B1 inhibitors with statins should be closely monitored in practice; However, it should be noticed that OATP inhibitors are not so numerous, including rifampin, cyclosporine, and some HIV-antiprotease and macrolides [17].

Such differences in the DDI pattern of statins may have consequences in the choice of a statin to be prescribed in patients, especially for polymedicated patients. Such differences should be also be considered by the pharmacology and therapeutics committee of our institutions for the choice the statin(s) to be integrated in the medication formulary. Moreover, if a substitution has to be made in the drug treatment of patient during its hospitalization as a result on a nonavailability of the statin prescribed within the institution, the health professionals in charge of the medical reconciliation should paid attention to the statin substitution in order to avoid generation of DDIs.

\subsection{Prevalence of drug-drug interactions}

In order to understand DDI profiles of the marketed statins we studied their DDI profile (by statin, by level of severity) according to 5 different DDBs given the variations reported in the literature. This enabled us to evidence dissimilarities between DDB on DDI prevalence for a given severity level.

If we consider DDIs which are contraindicated (level 1 in our study), we showed that DDI prevalence fluctuated from $0.15 \%$ to $0.2 \%$. No dissimilarities have been observed in DDBs from the same country. However, for atorvastatin and rosuvastatin, we observed higher DDI prevalence for French DDBs compared to US DDBs. On the opposite, simvastatin showed a 
higher DDI prevalence for US DDBs compared to French DDBs. According to US DDBs, the drug interaction : rosuvastatin-cyclosporine is not considered as contraindicated as it is by French DDBs. Conversely, French DDBs did not mentioned simvastatin-cyclosporine as a contraindication in the version we used in our study (version: 2016-08-12). However, Thesaurus DDB identified simvastatine-cyclosporine as a contraindication after the end of our study in September 2016 and mentioned it in a supplementary material [8]. It can be quite surprising that a contraindication was not mentioned by a national drug agency in the national thesaurus for such widely prescribed drugs. Such missing might also be observed in DDB's based or not on a national standard.

Such DDI between cyclosporine and simvastatin is of paramount importance given that fact that transplant patients are frequently treated for hypercholesterolemia induced by cyclosporine, and with the fact that this interaction is very significant with a 4.1 fold (DDI predictor) increase in statins exposure potentially exposing frail patients to rhabdomyolysis [22-24]. Indeed, physicians should be aware of such differences through DDB's especially for level 1 DDI (i.e., contraindication).

On level of severity 2, we analyzed prevalence of DDI's generally avoided. It ranged from $1.2 \%$ for Thesaurus and Vidal to $9.3 \%$ for Drugs.com. Prevalence of statin DDI were generally higher with Drugs.com and Micromedex DDBs compared to French DDBs. If we consider the most frequent DDI on the level of severity 2 (Figure 3b), the three most frequent DDI for Drugs. Com (simvastatine-amlodipine, atorvastatin-colchicine, atorvastatintacrolimus) and for Micromedex (atorvastatin-diltiazem, atorvastatin-digoxine, atorvastatinedomperidone) are not listed with the same level of severity or not listed at all by French DDBs. For example, atorvastatin-colchicine, simvastatin-amlodipine, atorvastatin-diltiazem are mentioned as precaution of use by French DDBs. Hence, the ranking of DDI's within a 
therapeutic class can vary according to DDI screening programs, thus impeding the comparability between studies.

On level of severity 3 (precaution of use), the prevalence of DDI's ranged from $21.5 \%$ to 25.3\% according to French DDBs and Micromedex, respectively. A very significant difference was observed in the prevalence of potential statin DDIs according to Drugs.com (49\%). Such a difference questions on the true clinical relevance of the DDIs reported by Drugs.com should be known by physicians. Indeed, this could participate to alert-fatigue phenomenon that should be avoided in order to focus on DDIs relevant to patients [25].

\subsection{Comparison between DDBS}

This study highlighted that there are differences in prevalence of statin DDIs' among our selected DDBs (Table 2).

The level of agreement between DDBs fluctuates depending on the drug pairwise compared. Within french DDBs, we observed small dissimilarities $(0.1 \%)$ explained by the fact that these 3 DDBs share the same DDI screening program based on Thesaurus DDIs' list. Micromedex and Drugs.com that did not share the same DDI screening program displayed higher dissimilarities than French DDBs (29.4\% for Micromedex vs $52.4 \%$ for Drugs.com, Table 2).

A higher concordance was observed between Micromedex and French DDBs than between French DDBs and Drugs.com. Such dissimilarities have been observed in other publications mostly between US DDBs [26-30]. 
A study pointed out the lack of standardization in inclusion DDI procedure assessment, and in

Furthermore, there are also heterogeneity in the reliability sources to establish evidence to support DDI and clinical relevance. Indeed, publications mentioned the lack of high quality evidence to support DDI [31-33]. Indeed, the first element suggesting the existence of a DDI is reported in the summary product characteristics of newly registered drugs. DDIs are often studied based on their pharmacokinetic (PK) and/or pharmacodynamic (PD) properties. Medical agencies (FDA and EMA) have quite recently published guidelines to help pharmaceutical companies to study drug-drug interactions, either at the in vitro and in vivo levels $[34,35]$. Based on these studies, extrapolation is then made to determine DDI existence to the general population, and for potential precipitant drugs [31-32,36-37]. Consequently, not every possible DDIs are tested in randomized controlled trials to confirm their existence and if there are tested this is mainly on small population sample [37]. This is source of potential theoretical DDIs. 
According to Van Roon et al, a clinically relevant DDI occurs when the therapeutic activity and/or toxicity of a drug is changed to such an extent that a dosage adjustment of the medication or medical intervention may be required [38].

Clinical relevance procedures are difficult to conduct for multiple reasons. Firstly, interpatient variability makes it difficult to extrapolate DDI consequences to general population. Some adverse reactions related to DDI can have indeed different gradation in seriousness depending on individual patient or disease characteristics. Indeed, patient with renal failure presented higher risk of DDI especially when renal elimination drugs are involved. Secondly, there is a lack of information related to the incidence of adverse drug reaction resulting to a DDI. Hence, observational interactions studies may be of interest to address this point.

Different panel's experts are in favor of more individualized standard procedure integrating patients' characteristics and comorbidities in the DDI reporting to health professionals $[31,32,38]$. However, DDB's are not frequently integrated to patients characteristics in electronic health records of our hospitals so that DDIs reported to health professionals are sometimes not relevant for a specific patient and also over-reported contributing to the alertfatigue phenomenon [25].

\section{Limitations}

Several limitations of the present study should be mentioned. The first is that we did not achieve a comparison of DDI profiles before and after hospitalization. Indeed, hospitalized patients might be more exposed to DDIs compared to patients in ambulatory care as a result of potential specific treatments administered to patients. This was showed by a study which analyzed medications of 851 patients during their hospital stay. They concluded that almost half of the major to moderate DDIs were created during hospitalization [39]. 
The second limitation arises from the fact that this study is monocentric, and has been performed in patients hospitalized in a university hospital. This might represent a potential bias since patients hospitalized in a university hospital have usually more severe clinical conditions. Thus, patients either in ambulatory setting or hospitalized in other settings could have differences in nature or prevalence of DDIs. A third limitation resides in the fact that this study is not totally extrapolable since pitavastatin, which is a new statin but not yet marketed in France, was not included in our study. A forth limitation resides in the fact that the clinical consequences of potential DDIs were not investigated.

\section{Conclusion and Perspectives}

This study showed that the DDI profiles of the statins was different with a high prevalence of CYP3A4-based interactions for lipophilic statins. However, the more significant DDIs (level 1 : contraindication) were reported for transporter-based DDI involving OATP1 influx transporter. Such differences are to be considered for the optimal choice of statin to be referenced by the P \& T committee of our institutions.

The use of several DDB's in our study gave a broader perspective in the evaluation of potential DDIs, and allowed to assess the reliability of DDB for the detection of DDIs. Such differences should be considered by editors of DDB providing tools for DDI interaction detection and national health authorities in order to assess the origin of such differences, and to address these differences.

Evidence from the real-world data based on high-quality observational studies on DDI from clinical data warehouse are one way to improve the quality of DDI documentation, and could be useful for national health authorities as well as for the formation of health professionals to inform on DDI of particular concern. 


\section{References}

1. Gu Q, Paulose-Ram R, Burt VL, Kit BK. Prescription cholesterol-lowering medication use in adults aged 40 and over: United States, 2003-2012. NCHS Data Brief. 2014 Dec;(177):1-8.

2. ANSM : Agence nationale de sécurité du médicament et des produits de santé [Internet]. [cited 2017 May 17]. Available http://www.ansm.sante.fr/searchengine/detail/(cis)/69358900/(limit)/90

3. Ganga HV, Slim HB, Thompson PD. A systematic review of statin-induced muscle problems in clinical trials. Am Heart J. 2014 Jul;168(1):6-15.

4. Law M, Rudnicka AR. Statin safety: a systematic review. Am J Cardiol. 2006 Apr 17;97(8A):52C-60C.

5. Stewart D, Mair A, Wilson M, Kardas P, Lewek P, Alonso A, et al. Guidance to manage inappropriate polypharmacy in older people: systematic review and future developments. Expert Opin Drug Saf. 2017 Feb;16(2):203-13.

6. Thai M, Reeve E, Hilmer SN, Qi K, Pearson S-A, Gnjidic D. Prevalence of statin-drug interactions in older people: a systematic review. Eur J Clin Pharmacol. 2016 May;72(5):51321.

7. Egger SS, Rätz Bravo AE, Hess L, Schlienger RG, Krähenbühl S. Age-related differences in the prevalence of potential drug-drug interactions in ambulatory dyslipidaemic patients treated with statins. Drugs Aging. 2007;24(5):429-40.

8. Interactions médicamenteuses - ANSM : Agence nationale de sécurité du médicament et des produits de santé [Internet]. [cited 2017 May 17]. Available from: http://ansm.sante.fr/Dossiers/Interactions-medicamenteuses/Interactionsmedicamenteuses/(offset)/0

9. VIDAL Hoptimal [Internet]. VIDAL France. [cited 2017 May 17]. Available from: http://www.vidalfrance.com/solutions/solutions-professionnels/vidal-hoptimal/

10. Thériaque [Internet]. [cited 2017 May 17]. Available from: http://www.theriaque.org/apps/contenu/accueil.php

11. Kongsholm GG, Nielsen AKT, Damkier P. Drug interaction databases in medical literature: transparency of ownership, funding, classification algorithms, level of documentation, and staff qualifications. A systematic review. Eur J Clin Pharmacol. 2015 Nov;71(11):1397-402.

12. Drug Interactions Checker - For Drugs, Food \& Alcohol [Internet]. Drugs.com. [cited 2017 May 17]. Available from: https://www.drugs.com/drug_interactions.html

13. Truven Health Products: Please Login [Internet]. [cited 2017 May 17]. Available from: https://www.micromedexsolutions.com/home/dispatch 
14. Delamarre D, Bouzille G, Dalleau K, Courtel D, Cuggia M. Semantic integration of medication data into the EHOP Clinical Data Warehouse. Stud Health Technol Inform. 2015;210:702-6.

15. Hu M, Tomlinson B. Evaluation of the pharmacokinetics and drug interactions of the two recently developed statins, rosuvastatin and pitavastatin. Expert Opin Drug Metab Toxicol. 2014 Jan;10(1):51-65.

16. Hirota T, Ieiri I. Drug-drug interactions that interfere with statin metabolism. Expert Opin Drug Metab Toxicol. 2015;11(9):1435-47.

17. Bellosta S, Corsini A. Statin drug interactions and related adverse reactions. Expert Opin Drug Saf. 2012 Nov;11(6):933-46.

18. The Pharmacogenomics Knowledge Base [Internet]. PharmGKB. [cited 2017 May 17]. Available from: https://www.pharmgkb.org

19. UCSF-FDA TransPortal [Internet]. [cited 2017 May 17]. Available from: http://transportal.compbio.ucsf.edu/

20. DrugBank [Internet]. [cited 2017 Jan 13];Available from: https://www.drugbank.ca/

21. Patel M, Taskar KS, Zamek-Gliszczynski MJ. Importance of Hepatic Transporters in Clinical Disposition of Drugs and Their Metabolites. J Clin Pharmacol. 2016 Jul;56 Suppl 7:S23-39.

22. Wiggins BS, Saseen JJ, Page RL, Reed BN, Sneed K, Kostis JB, et al. Recommendations for Management of Clinically Significant Drug-Drug Interactions With Statins and Select Agents Used in Patients With Cardiovascular Disease: A Scientific Statement From the American Heart Association. Circulation. 2016 Nov 22;134(21):e468-95.

23. Campana C, Regazzi MB, Buggia I, Molinaro M. Clinically significant drug interactions with cyclosporin. An update. Clin Pharmacokinet. 1996 Feb;30(2):141-79.

24. Kalliokoski A, Niemi M. Impact of OATP transporters on pharmacokinetics. Br J Pharmacol. 2009 Oct;158(3):693-705.

25. Abarca J, Colon LR, Wang VS, Malone DC, Murphy JE, Armstrong EP. Evaluation of the performance of drug-drug interaction screening software in community and hospital pharmacies. J Manag Care Pharm. 2006 Jun;12(5):383-9.

26. Ramos GV, Guaraldo L, Japiassú AM, Bozza FA. Comparison of two databases to detect potential drug-drug interactions between prescriptions of HIV/AIDS patients in critical care. J Clin Pharm Ther. 2015 Feb;40(1):63-7.

27. Fernández de Palencia Espinosa MÁ, Díaz Carrasco MS, Alonso Romero JL, de la Rubia Nieto A, Espuny Miró A. Potential drug-drug interactions in oncological adult inpatients at a Spanish hospital: epidemiology and risk factors. Int J Clin Pharm. 2015 Dec;37(6):1021-7. 
28. Abarca J, Malone DC, Armstrong EP, Grizzle AJ, Hansten PD, Van Bergen RC, et al. Concordance of severity ratings provided in four drug interaction compendia. $\mathrm{J}$ Am Pharm Assoc (2003). 2004 Apr;44(2):136-41.

29. Wang LM, Wong M, Lightwood JM, Cheng CM. Black box warning contraindicated comedications: concordance among three major drug interaction screening programs. Ann Pharmacother. 2010 Jan;44(1):28-34.

30. Vonbach P, Dubied A, Krähenbühl S, Beer JH. Evaluation of frequently used drug interaction screening programs. Pharm World Sci. 2008 Aug;30(4):367-74.

31. Scheife RT, Hines LE, Boyce RD, Chung SP, Momper JD, Sommer CD, et al. Consensus recommendations for systematic evaluation of drug-drug interaction evidence for clinical decision support. Drug Saf. 2015 Feb;38(2):197-206.

32. Phansalkar S, Desai AA, Bell D, Yoshida E, Doole J, Czochanski M, et al. High-priority drugdrug interactions for use in electronic health records. J Am Med Inform Assoc. 2012 Oct;19(5):735-43.

33. Vitry AI. Comparative assessment of four drug interaction compendia. Br J Clin Pharmacol. 2007 Jun;63(6):709-14.

34. Food and Drug Administration. Guidance for industry: drug interaction studies - study design, data analysis, and implications for dosing and labeling recommendations: draft guidance. 2012. US Department of Health and Human Services. [cited 12/1/2014]; Available from: http://www.fda.gov/downloads/drugs/guidancecomplianceregulatoryinformation/guidances/uc m292362.pdf.

35. Guideline on the investigation of drug interaction shttp://www.ema.europa.eu/docs/en_GB/document_library/Scientific_guideline/2012/07/WC5 00129606.pdf

36. Caccia S, Garattini S, Pasina L, Nobili A. Predicting the clinical relevance of drug interactions from pre-approval studies. Drug Saf. 2009;32(11):1017-39.

37. Horn JR, Hansten PD, Chan L-N. Proposal for a new tool to evaluate drug interaction cases. Ann Pharmacother. 2007 Apr;41(4):674-80.

38. van Roon EN, Flikweert S, le Comte M, Langendijk PNJ, Kwee-Zuiderwijk WJM, Smits P, et al. Clinical relevance of drug-drug interactions : a structured assessment procedure. Drug Saf. 2005;28(12):1131-9.

39. Vonbach P, Dubied A, Krähenbühl S, Beer JH. Prevalence of drug-drug interactions at hospital entry and during hospital stay of patients in internal medicine. Eur J Intern Med. 2008 Oct;19(6):413-2 


\begin{tabular}{|c|c|c|c|c|c|c|c|}
\hline Characteristics & Simvastatin & Atorvastatin & Lovastatin & Pitavastatin & Fluvastatin & Pravastatin & Rosuvastatin \\
\hline log P predicted ALOGPS & 4.68 & 4.41 & 4.11 & 3.75 & 3.69 & 2.23 & 1.47 \\
\hline $\log P$ exp & 4.51 & 5.7 & 4.26 & - & 4.5 & 0.59 & 0.13 \\
\hline Bioavailability & $<5$ & 15 & $<5$ & 50 to 60 & 10 to 35 & 20 & 20 \\
\hline Protein binding $\%$ & 95 & $>98$ & $>95$ & $>99$ & $>98$ & 50 & 90 \\
\hline Half-life (hours) & 5 & $15-30$ & 5 & 13 & 5 & 5 & $15-30$ \\
\hline Hepatic extraction & $>80$ & $>70$ & $>70$ & $?$ & $>70$ & 45 & 60 \\
\hline Extent of metabolism & +++ & +++ & +++ & ++ & +++ & + & + \\
\hline \multicolumn{8}{|l|}{ Metabolism by CYP450 } \\
\hline major route & CYP3A4 & CYP3A4 & CYP3A4 & NO & CYP2C9 & NO & NO \\
\hline minor route & CYP2C8 & CYP2C8 & CYP2C8 & CYP2C9-CYP2C8 & CYP3A4-CYP2C8 & CYP3A4 & CYP2C9-2C19 \\
\hline Glucuronidation (UGT1A3) & + & ++ & + & ++ & 0 & 0 & + \\
\hline Sulfonation & & & & & & +++ & \\
\hline \multicolumn{8}{|l|}{ Transporters } \\
\hline $\begin{array}{l}\text { Contribution of OATB1B1-1B3 to } \\
\text { uptake }\end{array}$ & major & major & minor & minor & minor & major & major \\
\hline \multirow[t]{5}{*}{ influx } & SLC-1B1 & SLC-1B1 & $S L C-1 B 1$ & SLC-1B1 & SLC-1B1 & SLC-1B1 & SLC-1B1 \\
\hline & & SLC-2B1 & & $S L C-1 B 3$ & SLC-1B3 & SLC-1B3 & SLC-1B3 \\
\hline & & & & & SLC-2B1 & SLC-2B1 & SLC-2B1 \\
\hline & & & & & & & SLC-1A2 \\
\hline & & & & & & & SLC-1A1 \\
\hline & & & & & & & \\
\hline \multirow[t]{4}{*}{ efflux } & ABCB1 & ABCB1 & $A B C B 1$ & $A B C B 1$ & $A B C G 2$ & ABCB1 & ABCB1 \\
\hline & ABCG2 & ABCG2 & & $A B C C 2$ & & $\mathrm{ABCC2}$ & $A B C C 2$ \\
\hline & & & & $A B C G 2$ & & ABCG2 & ABCG2 \\
\hline & & & & & & ABCB11 & \\
\hline
\end{tabular}

Table 1 : Main physico-chemical and pharmacokinetics properties of statins. Lovastatin and pitavastatin are not marketed in France and have been included for purpose of comparison. 


\begin{tabular}{ccc}
\hline Drug databases & $\begin{array}{c}\text { percentage of patients detected } \\
\text { with statin drug-drug interactions }\end{array}$ & $\begin{array}{c}\text { number of listed statin } \\
\text { drug-drug interactions }\end{array}$ \\
\hline Thesaurus & $22,5(2363)$ & 128 \\
\hline Theriaque & $22,5(2360)$ & 131 \\
\hline Vidal & $22,5(2369)$ & 217 \\
\hline Micromedex & $29,4(3087)$ & 565 \\
\hline Drugs.com & $52,2(5481)$ & \\
\hline
\end{tabular}

Table 2 : Prevalence of drug-drug interactions in percentage (absolute number), and number of listed drug-drug interactions according to each drug database. 


\begin{tabular}{|c|ccccc|}
\hline Drug databases & Theriaque & Thesaurus & Vidal & Micromedex & Drugs.com \\
\hline $\mathbf{1}$ & & & & & \\
\hline $\mathbf{2}$ & $0.2(26)$ & $0.2(22)$ & $0.2(22)$ & $0.16(17)$ & $0.15(16)$ \\
\hline $\mathbf{3}$ & $1.3(134)$ & $1.2(128)$ & $1.2(128)$ & $6.2(652)$ & $9.3(980)$ \\
\hline & $21.5(2,254)$ & $21.6(2,270)$ & $21.6(2,270)$ & $25.3(2,661)$ & $48.70(5,117)$ \\
\hline
\end{tabular}

Table 3 : Prevalence of drug-drug interactions in percentage (and absolute number) classified by level of severity and by drug database.

Level of severity 1 : contraindicated, Level of severity 2 : generally avoided, Level of severity 3 : precaution for use 


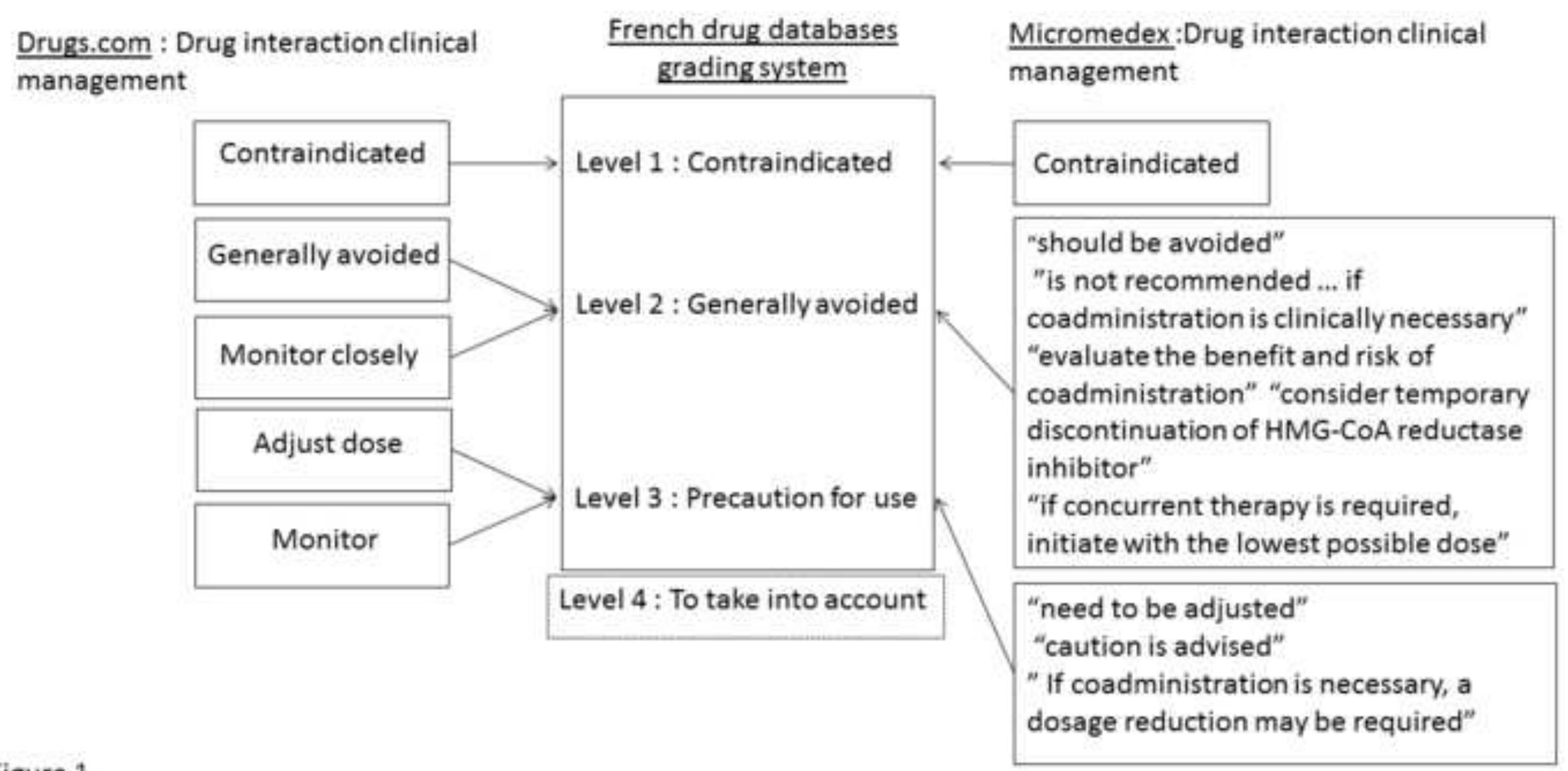

Figure 1

(n) "is not recommended ... if coadministration is clinically necessary"

"evaluate the benefit and risk of coadministration" "consider temporary discontinuation of $\mathrm{HMG}-\mathrm{COA}$ reductase inhibitor"

"if concurrent therapy is required, initiate with the lowest possible dose"

caution is advised" dosage reduction may be required ${ }^{\prime \prime}$

\begin{tabular}{l|l|}
\hline \multicolumn{1}{|c|}{ French drug databases } \\
Lrading system
\end{tabular}




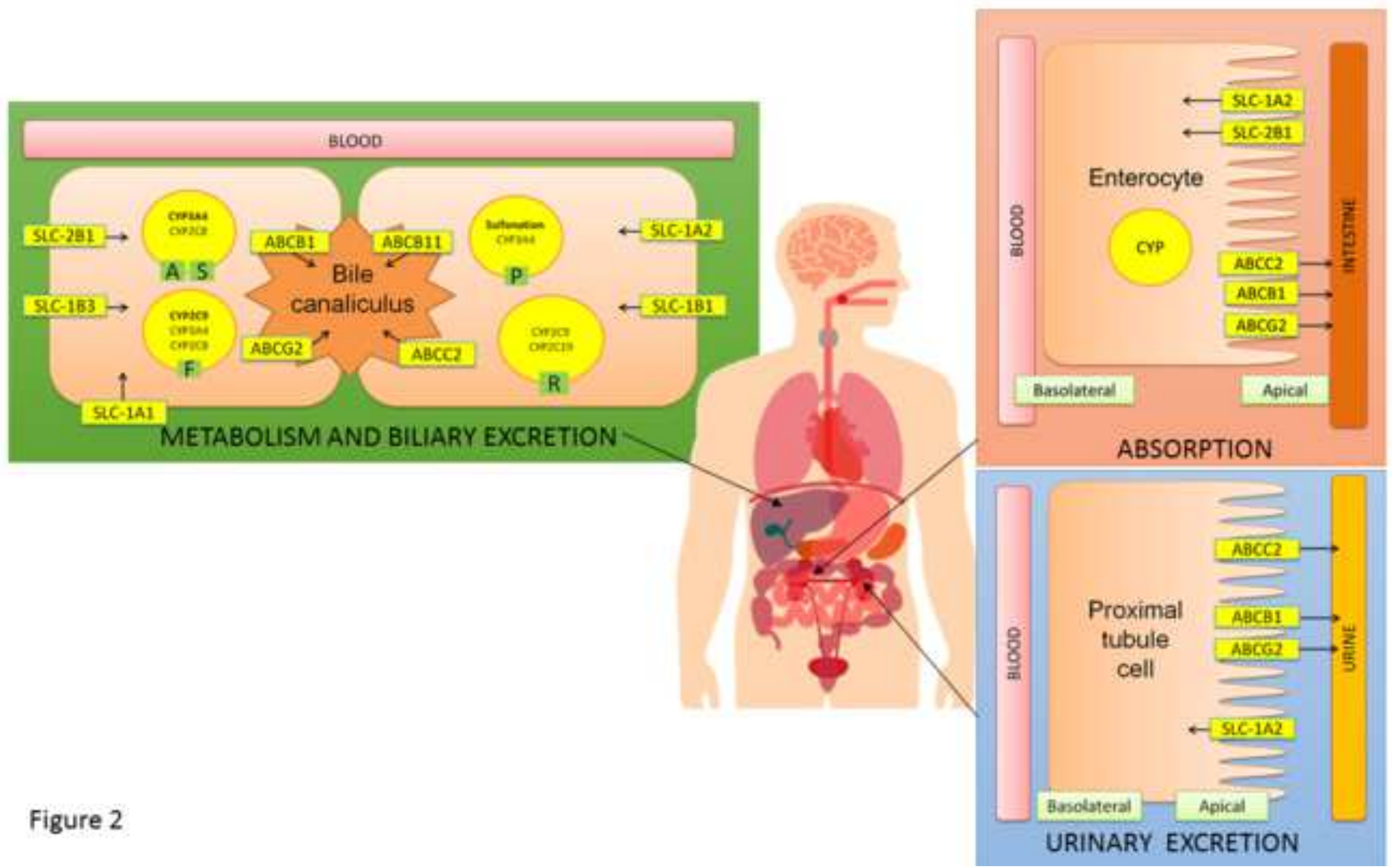




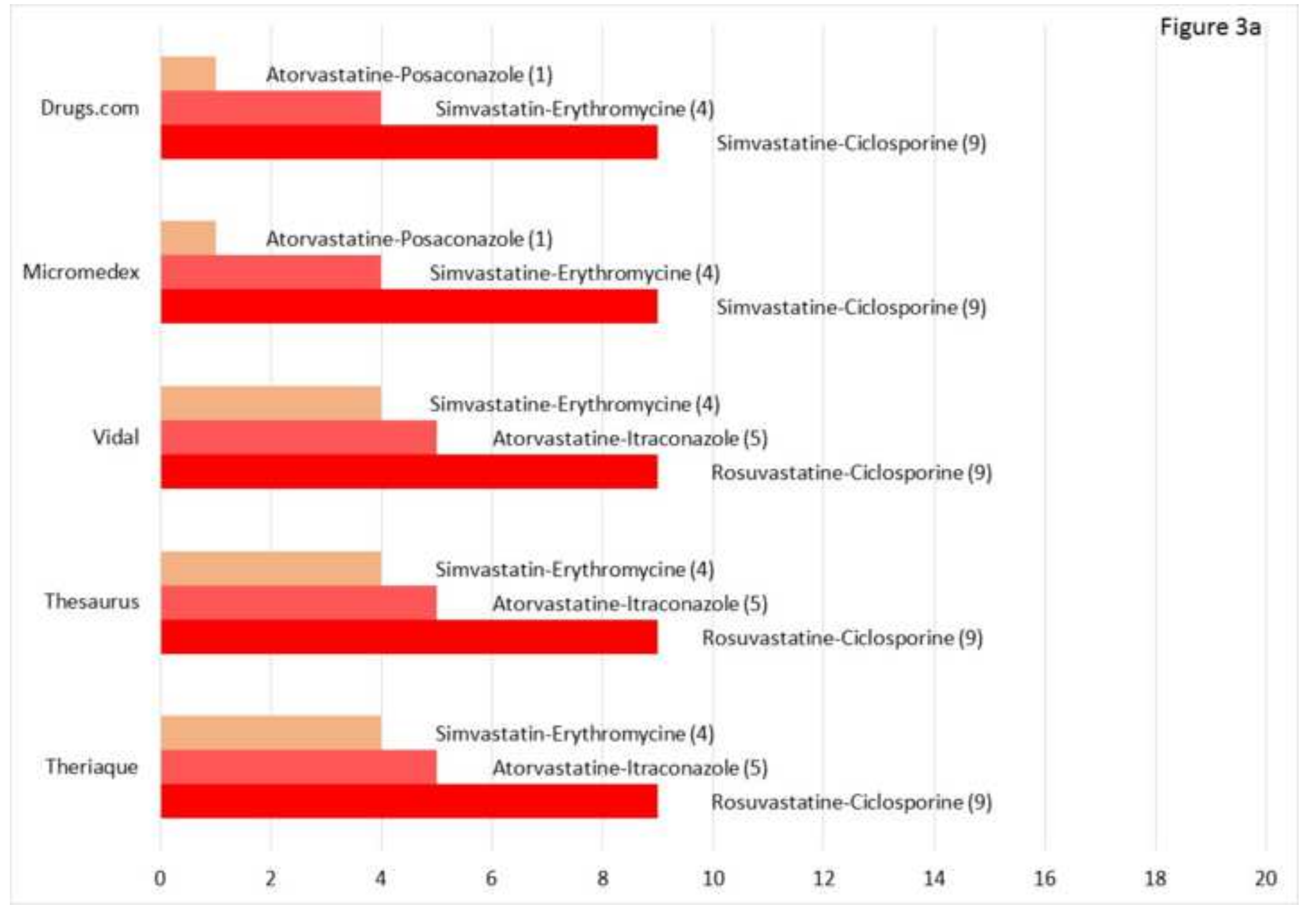

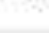

‥




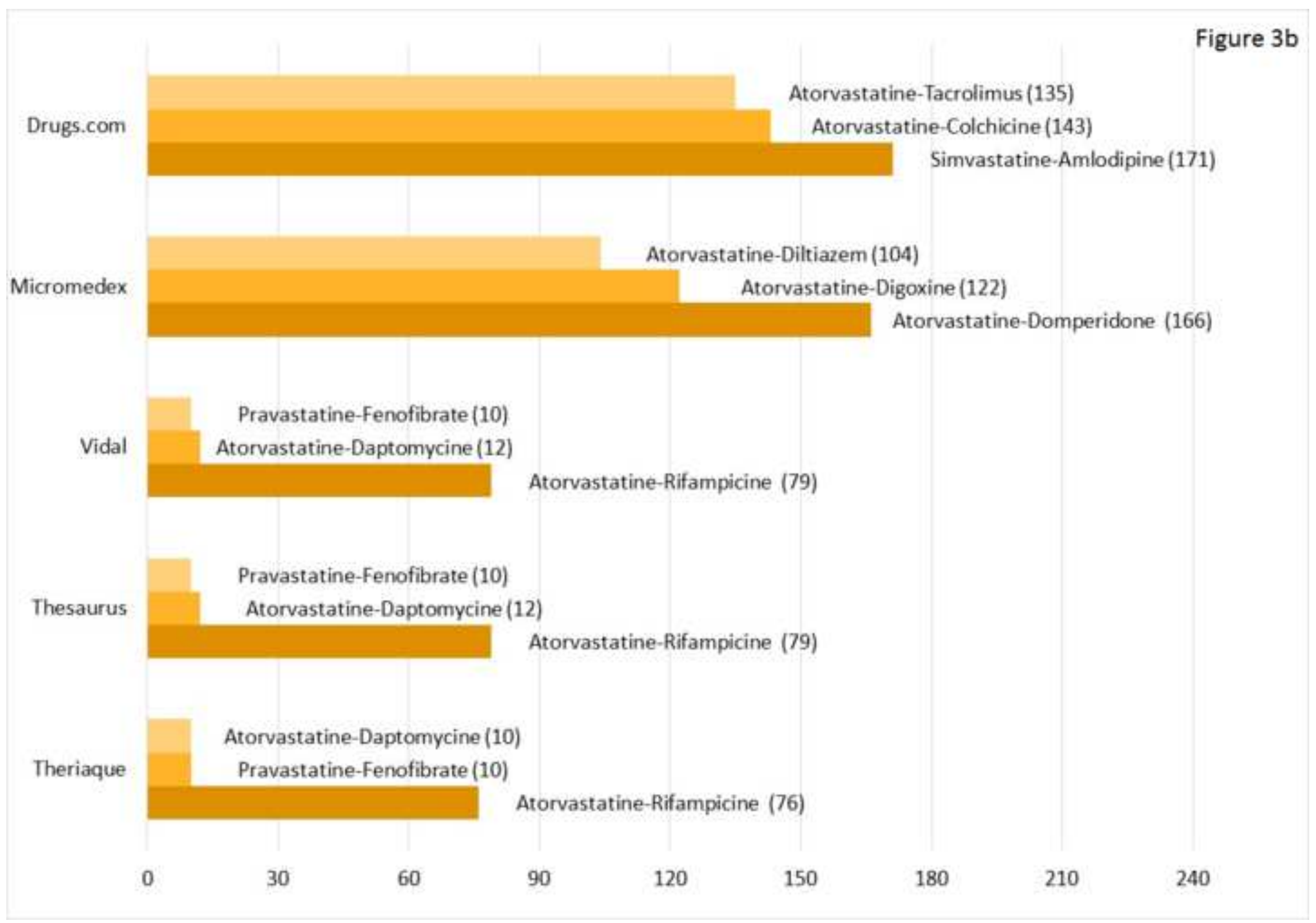




Theriaque Thesaurus Vidal Micromedex Drugs.com

\section{ATORVASTATINE $\%(n)$}

$n=7259$

$\begin{array}{lllll}1 & 0.1(9) & 0.3(21) & 0.1(9) & 0.04(3) \\ 2 & 1.4(100) & 1.4(100) & 1.4(100) & 6.9(502) \\ 3 & 18.9(1374) & 19.0(1378) & 19.0 & 27.6(2005) \\ & & & (1378) & \end{array}$

\section{SIMVASTATINE}

$\mathrm{n}=1155$

$\begin{array}{llllc}1 & 0.3(4) & 0.3(4) & 0.3(4) & 1.2(14) \\ 2 & 1.6(19) & 1.2(14) & 1.2(14) & 4.6(53) \\ 3 & 28,7(331) & 29.0(335) & 29.0(335) 40.8(471)\end{array}$

ROSUVASTATINE

$n=1190$

$\begin{array}{lllll}1 & 1.0(12) & 0.8(9) & 0.8(9) & 0.0(0) \\ 2 & 0.1(1) & 0.3(4) & 0.3(4) & 0.3(4) \\ 3 & 15.0(179) & 15.0(179) & 15.0(179) & 12.6(150)\end{array}$

PRAVASTATINE

$n=2535$

$\begin{array}{llllll}1 & 0.04(1) & 0.0(0) & 0.0(0) \quad 0.0(0) & 0.0(0) \\ 2 & 0.6(14) & 0.4(10) & 0.4(10) \quad 3.7(93) & 4.7(119) \\ 3 & 17.2(436) & 17.6(445) & 17.6(445) 2.0(50) & 15.5(392)\end{array}$

\section{$0.03(2)$}

7.4 (536)

$56.9(4130)$

Extent of

metabolism
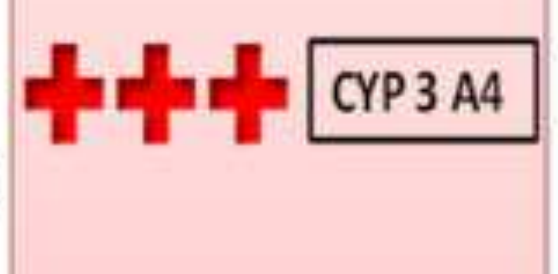

FLUVASTATINE

$n=1376$

\begin{tabular}{llllll}
1 & $0.0(0)$ & $0.0(0)$ & $0.0(0)$ & $0.0(0)$ & $0.0(0)$ \\
2 & $0.2(3)$ & $0.2(3)$ & $0.2(3)$ & $0.4(6)$ & $0.4(6)$ \\
3 & $1.2(17)$ & $1.2(17)$ & $1.2(17)$ & $2.8(39)$ & $2.0(27)$ \\
\hline
\end{tabular}
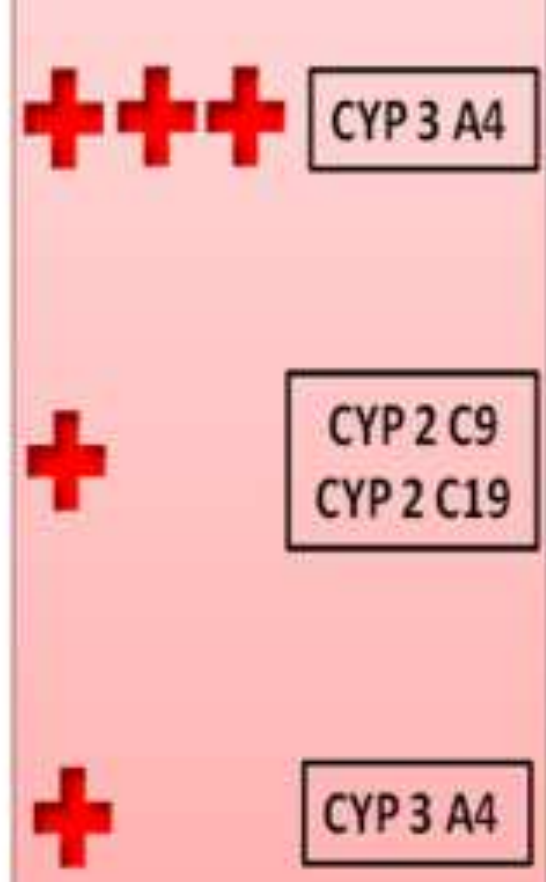

.

